\title{
Surface Science and Stability of Networks Prepared from Hydroxy-Terminated Polydimethylsiloxane and Methyltriethoxysilane
}

\author{
Kenneth J. Wynne, ${ }^{1,2 *}$ T. Ho, ${ }^{1,3}$ E. E. Johnston ${ }^{1,3}$ and Sharon A. Myers ${ }^{4}$ \\ ${ }^{1}$ Materials Chemistry Branch, Code 6120, Naval Research Laboratory, Washington, DC 20375, USA \\ ${ }^{2}$ Physical Science S\&T Division-331, Office of Naval Research, Arlington, VA 22217-5660, USA \\ ${ }^{3}$ Department of Chemistry, Virginia Polytechnic Institute and State University, Blacksburg, VA 24061- \\ 0212, USA \\ ${ }^{4}$ Naval Air Warfare Center, Weapons Division, Chemistry and Materials Branch, China Lake, CA 93555, \\ USA
}

\begin{abstract}
Polydimethylsiloxane (PDMS) hybrid networks have been prepared by the reaction of $\operatorname{PDMS}(\mathrm{OH})_{2}$, average molecular weight $26 \times 10^{3}, 43.6 \times 10^{3}$ and $58 \times 10^{3}$, and methyltriethoxysilane (MeTEOS, 10-60 wt\%) using a dibutyltin dilaurate or dibutyltin diacetate catalyst. By hydrolysis and homo- and cocondensation, MeTEOS forms a siliceous domain (MeSD) and acts as a crosslinker for the PDMS domain. Kinetic studies showed that high MeTEOS and catalyst concentrations and reduction of free surface area favor fast gelation and efficiency in converting MeTEOS to the MeSD. Under the water-sparse conditions utilized, cure was slow and substantial evaporative loss of MeTEOS occurred. (C) 1998 John Wiley \& Sons, Ltd.
\end{abstract}

Keywords: siloxane network; contact angle; solgel reaction; polydimethylsiloxane

Received 15 December 1997; accepted 23 February 1998

\section{INTRODUCTION}

As an alternative to coatings which prevent marine fouling by release of toxicants ('antifouling coat-

\footnotetext{
* Correspondence to: Kenneth J. Wynne, Materials Chemistry Branch, Code 6120, Naval Research Laboratory, Washington, DC 20375, USA.

Contract/grant sponsor: Strategic Environmental Research and Development Program (SERDP).

Contract/grant sponsor: US Office of Naval Research.
}

ings'), polydimethylsiloxane (PDMS) elastomeric coatings provide control by minimizing fouling adhesion strength ('fouling release' coatings). ${ }^{1-9}$ These PDMS coatings are room-temperature vulcanizing (RTV) elastomers which rely on sol-gel cure chemistry as described by Ulrich $^{5}$ and Mark. ${ }^{6}$ In this approach, alkoxysilane hydrolysis and homocondensation produce a siliceous domain (MeSD), while crosslinking is effected by cocondensation of alkoxysilane or alkoxy(hydroxy)silane species with $\mathrm{PDMS}(\mathrm{OH})_{2}$. This chemistry is basically the same as that used to prepare organicinorganic 'hybrid' materials, ${ }^{7}$ but the hydrolysis and condensation reactions occur under watersparse conditions. With a view toward examining cure kinetics, surface chemistry and the nature of the siliceous phase formed in ambient-temperature cure, we describe herein a series of networks with PDMS $\left[M_{\mathrm{n}}(26-58) \times 10^{3}\right]$ prepared by cure with methyltriethoxysilane.

\section{EXPERIMENTAL}

\section{Materials}

All materials were used as received. Silanol endcapped polydimethylsiloxanes (PDMS) $(\mathrm{OH})_{2}$ (United Chemical Technologies, Inc.) were obtained with viscosities and molecular weights of $1000 \mathrm{cS}$ $\left(26 \times 10^{3}\right), \quad 3500 \mathrm{cS}\left(43 \times 10^{3}\right)$, and $8000 \mathrm{cS}$ $\left(58 \times 10^{3}\right)$, according to the manufacturer's data. Methyltriethoxysilane (MeTEOS) and dibutyltin dilaurate were purchased from Aldrich Chemical Company. 


\section{Network synthesis}

Preparation of films for evaluation of wettability For each PDMS $(\mathrm{OH})_{2}$ molecular weight (MW), four levels of MeTEOS were utilized based on total weight of reactants $(10,15.6,25$, and $40 \mathrm{wt} \%$ for $\mathrm{MW}=26 \times 10^{3}$ and $43.6 \times 10^{3}$, and $15.6,25,40$ and $58.5 \mathrm{wt} \%$ for $\left.\mathrm{MW}=58 \times 10^{3}\right)$. Dibutyltin dilaurate catalyst comprised $1 \mathrm{wt} \%$. At room temperature in air, measured amounts of $\operatorname{PDMS}(\mathrm{OH})_{2}$ and MeTEOS were mixed in a glass vial (i.d. $1.9 \mathrm{~cm}$ ) with a mechanical stirrer for about 5 min, the catalyst was added and the mixing was continued for another $90 \mathrm{~min}$. The viscous material was then cast on an FEP (tetrafluoroethylenehexafluoropropylene copolymer) substrate or dipcoated on glass slides $(22 \mathrm{~mm} \times 50 \mathrm{~mm} \times$ $0.15 \mathrm{~mm}$ ). Samples were subsequently cured at $50-60{ }^{\circ} \mathrm{C}$ for $20 \mathrm{~h}$, and stored at room temperature. Alternatively, cure was effected at ambient temperature as shown in the kinetic studies described below.

\section{Preparation of samples for cure kinetics}

Measured amounts of PDMS $(\mathrm{OH})_{2}$ and MeTEOS were mixed with a magnetic stirrer for about $5 \mathrm{~min}$ in either a $10 \mathrm{ml}$ vial (i.d. $1.9 \mathrm{~cm}, 4-5 \mathrm{~g}$ material) or a $50 \mathrm{ml}$ beaker (i.d. $2.9 \mathrm{~cm}, 15 \mathrm{~g}$ material) followed by the addition of a measured amount of catalyst. The reactants were allowed to gel at room temperature in the container, and the progress of the reaction was monitored by measuring the mass of the mixture with a standard analytical balance.

\section{Characterization}

Dynamic contact angles were measured with a Cahn dynamic contact-angle analyzer (DCA-312), which is a Wilhelmy plate-type instrument. Unless noted otherwise, water was used as the probing liquid; it was purified with a Barnstead NANOpure ultrapure water system. Each measurement consisted of three cycles, the second and the third of which usually converged. The advancing and receding contact angles obtained in the last cycle are reported.

Stability of surface wettability was estimated by immersing representative samples in either aqueous $\mathrm{NaCl}(0.5 \mathrm{M})$ or NANOpure water containing $\mathrm{NaN}_{3}$ $(5 \mathrm{mM})$ for a period of 22 days, and monitoring water contact angles as a function of immersion time. Stability to mass loss was estimated by immersing samples in NANOpure water and weighing dried samples at $4 \mathrm{~h}$ intervals.
${ }^{29} \mathrm{Si}$ NMR magic-angle spinning (MAS) spectra were acquired using a Bruker MSL-200 operating at $39.8 \mathrm{MHz}$ for silicon. Typical spectra were recorded using single-pulse excitation with a recycle delay of $240 \mathrm{~s}, 200$ acquisitions, and MAS speeds ranging from 2.0 to $2.5 \mathrm{kHz}$. All spectra were acquired at ambient temperatures and externally referenced to octakis(trimethylsiloxy)silsesquioxane (Q8M8, downfield peak at $11.9 \mathrm{ppm})$.

\section{RESULTS AND DISCUSSION}

\section{Surface properties}

A survey of materials prepared with varying PDMS molecular weights and initial concentrations of MeTEOS was carried out. Under conditions of 50$60{ }^{\circ} \mathrm{C}$ cure, all MeTEOS-derived compositions cured into nonflowing solids when cured in a container. Three compositions with low percentages by weight of MeTEOS failed to cure to nonflowing films on either FEP or glass substrates. These included $26 \times 10^{3}$ and $43.6 \times 10^{3}$ PDMS $(\mathrm{OH})_{2}$ with $10 \mathrm{wt} \%$ MeTEOS and $58 \times 10^{3}$ PDMS $(\mathrm{OH})_{2}$ with 15.6 wt $\%$ MeTEOS.

To evaluate wettability, advancing and receding contact angles were measured and are listed in Table 1, each value being the average of measurements on four different specimens. In evaluating surface wettability, a high receding contact angle, $\theta_{\text {rec }}$, and low hysteresis $\left(\theta_{\Delta}=\theta_{\text {adv }}-\theta_{\text {rec }}\right)$ are taken as indicators of a high PDMS surface area fraction. ${ }^{8,9}$ The wettability of the films depends on the molecular weight of PDMS macromonomer and the initial weight fraction of MeTEOS. Results for $26 \times 10^{2}$ and $43.6 \times 10^{3} \operatorname{PDMS}(\mathrm{OH})_{2}$ are similar, with $\theta_{\text {adv }}$ decreasing, $\theta_{\text {rec }}$ increasing, and

Table 1 Contact angles (deg) of networks from PDMS $(\mathrm{OH})_{2}$ and MeTEOS

\begin{tabular}{lcccr}
\hline $\begin{array}{l}\text { PDMS }(\mathrm{OH})_{2} \\
(\mathrm{MW})\end{array}$ & $\begin{array}{c}\text { MeTEOS } \\
\text { (initial wt\%) }\end{array}$ & $\theta_{\text {adv }}$ & $\theta_{\text {rec }}$ & \multicolumn{1}{c}{$\theta_{\Delta}$} \\
\hline $26 \times 10^{3}$ & 15.6 & $115 \pm 1$ & $92 \pm 2$ & $23 \pm 3$ \\
$26 \times 10^{3}$ & 25 & $109 \pm 2$ & $93 \pm 1$ & $16 \pm 3$ \\
$26 \times 10^{3}$ & 40 & $104 \pm 2$ & $95 \pm 1$ & $9 \pm 3$ \\
$43.6 \times 10^{3}$ & 15.6 & $113 \pm 2$ & $91 \pm 1$ & $22 \pm 3$ \\
$43.6 \times 10^{3}$ & 25 & $108 \pm 2$ & $93 \pm 1$ & $15 \pm 3$ \\
$43.6 \times 10^{3}$ & 40 & $103 \pm 1$ & $95 \pm 1$ & $8 \pm 2$ \\
$58 \times 10^{3}$ & 25 & $108 \pm 3$ & $81 \pm 1$ & $27 \pm 4$ \\
$58 \times 10^{3}$ & 40 & $114 \pm 1$ & $88 \pm 1$ & $26 \pm 2$ \\
$58 \times 10^{3}$ & 58.5 & $104 \pm 3$ & $88 \pm 1$ & $16 \pm 4$ \\
\hline
\end{tabular}

Appl. Organometal. Chem. 12, 763-770 (1998) 
hysteresis therefore decreasing with increasing weight percentage of initial MeTEOS. For $58 \times 10^{3} \mathrm{PDMS}(\mathrm{OH})_{2}$ the results are less systematic, and hysteresis and receding contact angles are not as good as those achieved by using lower-MW $\mathrm{PDMS}(\mathrm{OH})_{2}$.

A set of samples based on $43.6 \times 10^{3}$ $\mathrm{PDMS}(\mathrm{OH})_{2}$ cured with $25 \%$ MeTEOS was used to investigate the effect on surface properties of immersion in a salt solution. Contact angles as a function of immersion time are shown in Table 2. Within experimental error, the surface tension for the $0.5 \mathrm{M} \mathrm{NaCl}$ solution (72.5 dyne $\mathrm{cm}^{-1}$ ) is the same as the surface tension for water (72.5 dyne $\mathrm{cm}^{-1}$ ), while the surface tension for the $5 \mathrm{mM} \mathrm{NaN}_{3}$ solution is about $4 \%$ lower $\left(69.8\right.$ dyne $\left.\mathrm{cm}^{-1}\right)$. Contact angles for water on the $43.6 \times 10^{3} \mathrm{PDMS} / 25 \%$ MeTEOS material just before immersion in the $\mathrm{NaCl}$ or $\mathrm{NaN}_{3}$ solutions were $\theta_{\mathrm{adv}}=106^{\circ}$ and $\theta_{\mathrm{rec}}=96^{\circ}$. (These values are slightly different from those listed in Table 1 and may reflect the fact that these samples had been

$$
\mathrm{yMeSi}(\mathrm{OEt})_{3}+1.5 \mathrm{H}_{2} \mathrm{O}+\mathrm{xHO}-\mathrm{PDMS}-\mathrm{OH}
$$

kept in air for four weeks before the immersion. The effect of cure time on contact angles is discussed in a separate section of this paper (see Fig. 3).) When the $5 \mathrm{mM} \mathrm{NaN}_{3}$ solution was used as the probing liquid, the contact angles were $\theta_{\text {adv }}=107^{\circ}$ and $\theta_{\text {rec }}=95^{\circ}$ before immersion. In comparison, when $0.5 \mathrm{M} \mathrm{NaCl}$ solution was used the contact angles were $\theta_{\mathrm{adv}}=106^{\circ}$ and $\theta_{\text {rec }}=88^{\circ}$.

Data in the upper portion of Table 2 are for samples which were aged in $\mathrm{NaCl}$ solution. The sample was removed and $\theta_{\mathrm{adv}}$ and $\theta_{\mathrm{rec}}$ were evaluated with water as a probing liquid (data on left-hand side) and the salt solution (data on righthand side). The corresponding data for aging in a $5 \mathrm{mM} \mathrm{NaN}_{3}$ solution are shown in the lower portion of Table 2. During the immersion, there was an increase in $\theta_{\text {adv }}$ for all probing liquids of about 4 $7^{\circ}$ and a decrease in $\theta_{\text {rec }}$ of $2-8^{\circ}$.

The observed decrease in $\theta_{\text {rec }}$ for water during immersion and the accompanying increase in hysteresis are interpreted in terms of a combination of increasing surface roughness, increasing hydrophilic character due to hydrolysis and the expression of hydrophilic sites at the surface. Surface roughness was not evaluated for these samples, but mass loss during water immersion of samples cured in a similar manner was observed (vide infra).
Surface roughness is known to increase advancing and decrease receding contact angles ${ }^{8,9}$. The first stage of this process may be a kind of nano-swelling caused by the interaction of water with near-surface siliceous domains. The use of a salt solution, particularly $\mathrm{NaN}_{3}$, as a probing liquid causes somewhat greater changes in receding contact angles than the use of water as a probing liquid.

\section{Kinetics for reactions using methyltriethoxysilane}

The kinetics of network formation of the PDMS $(\mathrm{OH})_{2} / \mathrm{MeTEOS}$ system was investigated. The variables examined included the ratio of reactants, the concentration of catalyst and the surface-to-volume ratio of the reactants. Effects of these factors were observed before and after gelation.

Network formation is illustrated in Eqn [1] using $26 \times 10^{3}$ PDMS and MeTEOS as starting materials.

The formula for the product shows the molecular

$$
\begin{array}{r}
\stackrel{\text { Catalyst }}{\longrightarrow}\left[26 \times 10^{3} \mathrm{PDMS}_{x}\left[\left(\mathrm{MeSiO}_{m}\right)(\mathrm{OH})_{n}\right]_{y}\right. \\
+(1.5-n / 2) \mathrm{H}_{2} \mathrm{O}+3 \mathrm{EtOH}
\end{array}
$$

weight of the PDMS macromonomer and the ratio of PDMS to MeSD in terms of subscripts $x$ and $y$. Water is consumed in hydrolysis and produced in condensation, and $2 m+n=3$. Equation [1] ignores water produced by the crosslinking reaction, i.e. condensation of PDMS $(\mathrm{OH})_{2}$ with any methylsilyl hydroxy- or alkoxy-containing species. This is a good approximation for networks with a high$\mathrm{MeSD}$ fraction. The ratio of $m$ to $n$, i.e. of $\mathrm{Si}-\mathrm{O}$ to $\mathrm{Si}-\mathrm{OH}$ in the MeSD, has two limits: considering only hydrolysis, $n=3(m=0)$, the MeSD would be methylsilicic acid-like $\left[\mathrm{MeSi}(\mathrm{OH})_{3}\right]$, while at the other limit, $m=1.5$ and the MeSD is $\mathrm{MeSiO}_{1.5}{ }^{29} \mathrm{Si}$ NMR spectroscopy (vide infra) suggests that the stoichiometry of the MeTEOS/PDMS compositions is at an intermediate level. In terms of mass loss, ethanol dominates mass-wise the volatile reaction products, the ratio of $m$ to $n$ is a second-order consideration, and weighing the reactant mixture proves to be a convenient means of following the reaction. The short residence time of ethanol in PDMS (hours) compared with long cure time (weeks) justifies following cure by monitoring the mass loss of ethanol. (To determine the residence time of ethanol in a PDMS matrix, a mixture of ethanol $(16 \mathrm{wt} \%)$ in PDMS $(8000 \mathrm{cS})$ was prepared in a $50 \mathrm{ml}$ beaker, and the mass loss of the mixture 
Table 2 Effects of immersion on surface properties of self-reinforced networks: contact angles (deg) as a function of time ${ }^{\mathrm{a}}$

\begin{tabular}{|c|c|c|c|c|c|c|c|c|}
\hline \multirow[b]{3}{*}{ Time (days) } & \multicolumn{4}{|c|}{ Immersed in $0.5 \mathrm{M} \mathrm{NaCl}$ solution } & \multicolumn{4}{|c|}{ Immersed in $0.005 \mathrm{M} \mathrm{NaN}_{3}$ solution } \\
\hline & \multicolumn{2}{|c|}{ Probing liquid $=$ water } & \multicolumn{2}{|c|}{$\begin{array}{l}\text { Probing liquid }=0.5 \mathrm{M} \\
\mathrm{NaCl} \text { soln. }\end{array}$} & \multicolumn{2}{|c|}{ Probing liquid $=$ water } & \multicolumn{2}{|c|}{$\begin{array}{c}\text { Probing liquid }=0.005 \mathrm{M} \\
\mathrm{NaN}_{3} \text { soln }\end{array}$} \\
\hline & $\theta_{\text {adv }}$ & $\theta_{\text {rec }}$ & $\theta_{\mathrm{adv}}$ & $\theta_{\text {rec }}$ & $\theta_{\text {adv }}$ & $\theta_{\text {rec }}$ & $\theta_{\text {adv }}$ & $\theta_{\text {rec }}$ \\
\hline 0 & 106 & 95 & 106 & 88 & 106 & 97 & 107 & 95 \\
\hline 2 & 110 & 93 & 108 & 91 & 112 & 95 & 108 & 88 \\
\hline 6 & 111 & 93 & 111 & 91 & 114 & 93 & 109 & 87 \\
\hline 9 & 112 & 93 & 113 & 92 & 114 & 93 & 112 & 89 \\
\hline 22 & 113 & 93 & 110 & 85 & 113 & 91 & 112 & 87 \\
\hline
\end{tabular}

${ }^{\mathrm{a}}$ The values shown are the average of two runs.

was monitored. The mass loss process is first order with respect to ethanol concentration. Thus, the residence time of ethanol in a PDMS matrix is on the order of hours at most, and is independent of concentration.) Related work suggests that residence time is little affected by the increasing viscosity of the matrix. (The diffusion of a tracer out of a high-molecular-weight polymer is only slightly faster than the diffusion of the same tracer out of a network of the same polymer; see, for example $\operatorname{Ref}^{10}$.)

Water is shown twice in Eqn [1] to emphasize its role in hydrolysis and as a product of condensation. The net water used and produced is zero if the reaction proceeds to completion $(m=1.5)$.

Gel time

Gel time was determined empirically as the moment when there was no observable flow of the reactants following an inversion of the vessel. Gelation has been investigated phenomenologically as well as theoretically. ${ }^{11}$ By the phenomenological approach viscosity is followed as a function of time; Fig. 1 shows a plot for a typical system, $66.0 \%$ PDMS $(\mathrm{OH})_{2}, 33.0 \%$ MeTEOS and $1.0 \%$ dibutyltin dilaurate, in air at ambient temperature, in a $10 \mathrm{ml}$ vial (i.d. $1.89 \mathrm{~cm}$ ) stirred with a spindle (No. 7 Brookfield). The viscosity increased slowly in the first $600 \mathrm{~min}$, then rapidly at about $630 \mathrm{~min}$. This pattern of rapid increase in viscosity at the gel point is usual for thermosetting systems, but the actual gel time depends on variables such as the relative weight-fraction of reactants and processing conditions. For example, when stirred magnetically the same system described above displayed a gel time of about $100 \mathrm{~min}$.

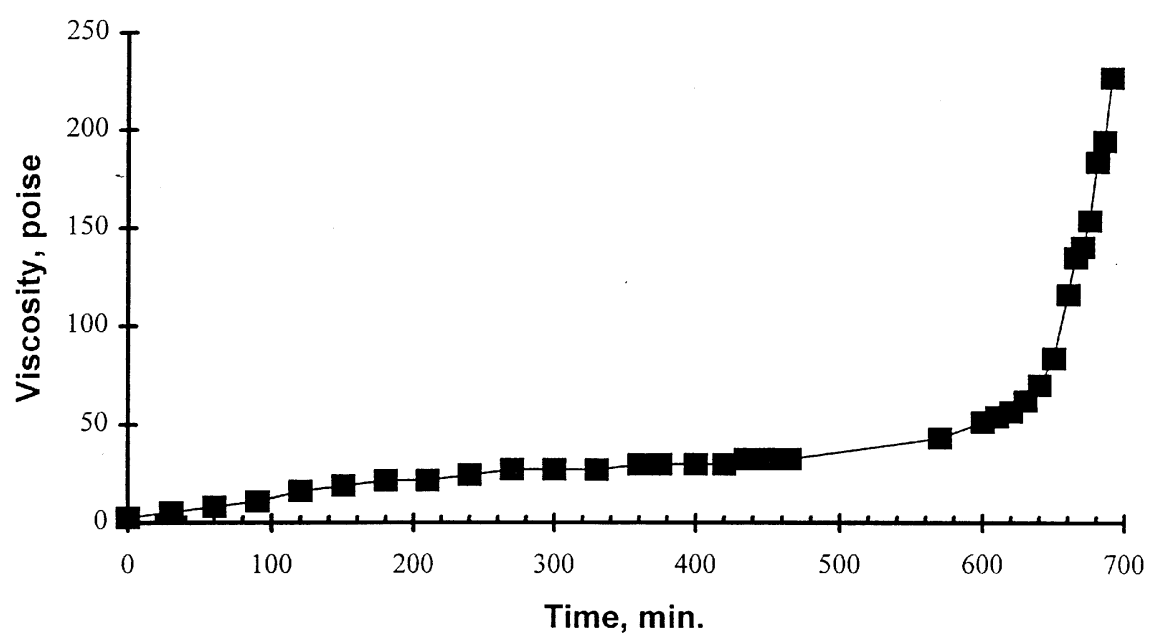

Figure 1 Viscosity as a function of time before gelation. The system, comprising 66.0 \%PDMS $(\mathrm{OH})_{2}, 33.0 \%$ MeTEOS and $1.0 \%$ DBTDL in a $10 \mathrm{ml}$ vial was stirred with a No. 7 spindle (Brookfield viscometer). 


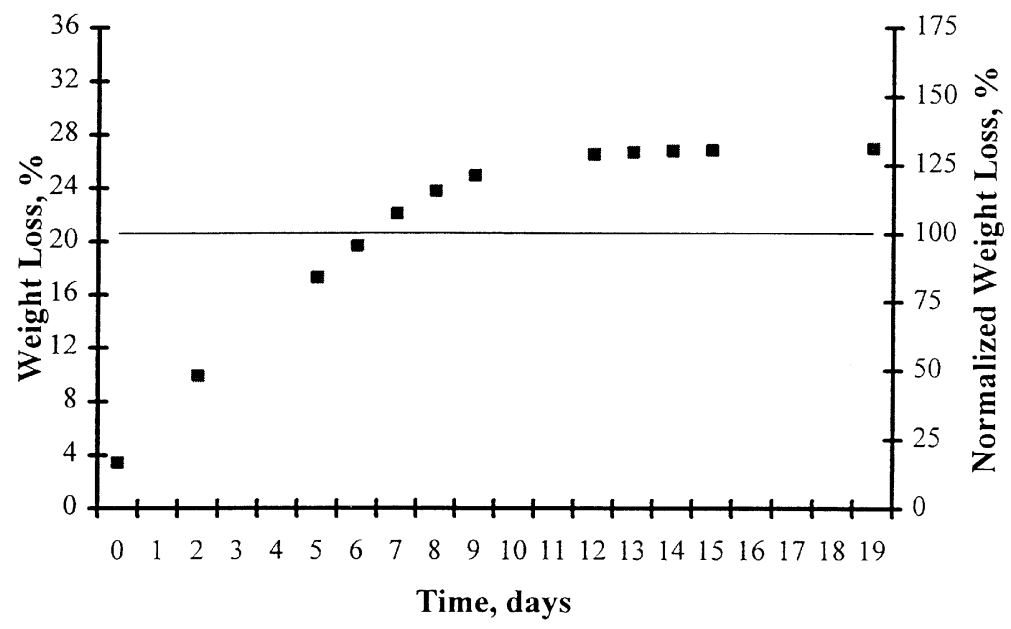

Figure 2 Mass loss as a function of time for the system comprising 65.9 $\%$ PDMS $(\mathrm{OH})_{2}, 33.1 \%$ MeTEOS and $1.0 \%$ DBTDL, in a $10 \mathrm{ml}$ vial, magnetically stirred. Weight is expressed as a percentage of the total weight of reactants. The scale on the right shows values normalized with respect to the theoretical maximum loss as ethanol.

\section{Kinetic Study on $26 \times 10^{3} \mathrm{PDMS}(\mathrm{OH})_{2-}$ MeTEOS: mass loss}

For kinetic study, a representative composition consisting of $65.9 \mathrm{wt} \% 26 \times 10^{3} \mathrm{PDMS}(\mathrm{OH})_{2}$, $33.1 \mathrm{wt} \%$ MeTEOS and $1.0 \mathrm{wt} \%$ DBTDL was allowed to react in a $10 \mathrm{ml}$ vial stirred magnetically at room temperature. The gel time was $100 \mathrm{~min}$. The mass loss as a function of time is shown in Fig. 2. A calculated mass loss was determined on the basis of Eqn [1], assuming that the siliceous domain had the stoichiometry $\mathrm{MeSiO}_{1.5}$. With this assumption, the calculated net loss of mass is $20.6 \%$ of the initial weight of reactants, as indicated by the horizontal line in Fig. 2. The scale on the right of Fig. 2 shows the measured mass loss normalized with respect to the calculated maximum. (A good first approximation is to assume the mass loss during the cure is totally in the form of ethanol, thus the ratio between the current loss and the calculated maximum gives the extent of reaction). The time of gelation is represented by day 0 in Fig. 2. The mass loss increases steadily for about one week after gelation, then the rate of increase drops gradually and levels off after about two weeks. The total mass loss at two weeks was $26.6 \%$, which exceeded the calculated value of $20.6 \%$, indicating that either MeTEOS or some volatile siloxane material, or both, were also lost from the system during cure.

The $26 \times 10^{3} \mathrm{PDMS}(\mathrm{OH})_{2}$ used in this study contains about 8 wt $\%$ low-molecular-weight spe- cies, most of which can be removed by extraction with acetone (T. Ho and K. J. Wynne, unpublished results). In an attempt to detect volatile species in PDMS $(\mathrm{OH})_{2}$, only $0.3 \%$ mass loss was detected under ambient temperature and pressure after two weeks. The contribution from the PDMS starting material to excess mass loss is therefore negligible.

The excess mass loss is due to volatility of MeTEOS and the weight fraction of the siliceous domain in the hybrid network is reduced accordingly. The mass loss measurements indicate the ratio of actual $(8.9 \%)$ to calculated $(15.7 \%)$ mass of siliceous domain is 0.57 . If the presence of $\mathrm{SiOH}$ is neglected, the stoichiometry of this material is $\left[26 \times 10^{3} \mathrm{PDMS}\right]\left[\left(\mathrm{MeSiO}_{1.5}\right]_{37.9}\right.$.

\section{Solid-state ${ }^{29} \mathrm{Si}$ NMR spectroscopy}

A PDMS-MeTEOS sample was prepared for solidstate ${ }^{29} \mathrm{Si}$ MAS NMR spectroscopy in order to determine composition by a method independent of mass loss. The initial composition was $67.1 \mathrm{wt} \%$ $26 \times 10^{3}$ PDMS $(\mathrm{OH})_{2}, 31.8 \mathrm{wt} \%$ MeTEOS and $1.0 \mathrm{wt} \%$ DBTDL. An intense, narrow peak at $-22.3 \mathrm{ppm}$ is due to silicon atoms in the PDMS domain. A peak at $-67.2 \mathrm{ppm}$ is assigned to silicon atoms in the MeSD (A peak at $-72.7 \mathrm{ppm}$ is an MAS sideband associated with the $-22.3 \mathrm{ppm}$ peak for the PDMS phase). In prior work on MeTEOSbased gels peaks have been assigned in the range 62-64 ppm to $\mathrm{T}^{3}\left(\mathrm{MeSiO}_{3}\right)$ and at 53-57 ppm to $\mathrm{T}^{2}$ 


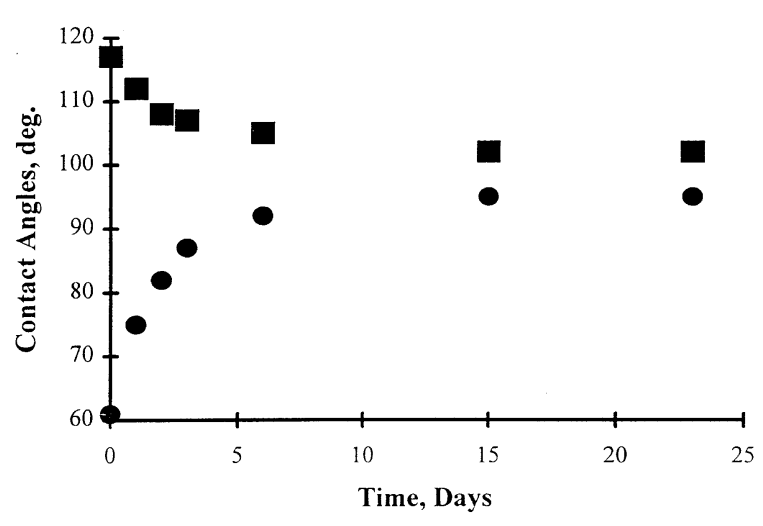

Figure 3 Advancing and receding contact angles of water on a film during cure for the system comprising $65.9 \%$ PDMS $(\mathrm{OH})_{2}, 33.1 \%$ MeTEOS and $1.0 \%$ DBTDL. $\theta_{\text {adv }}$ (advancing); $\left(\theta_{\text {rec }}\right.$ (receding).

$\left[\mathrm{MeSiO}_{2}(\mathrm{OH})\right]^{12}$. The weak intensity of the peak we observe does not allow an unambiguous assignment $\left(\mathrm{T}^{2}\right.$ vs $\mathrm{T}^{3}$ ), but it is clear from the irregular shape of this peak that multiple species are present.

Integrating the intensity of these peaks gives a ratio of $20: 1$ for $\mathrm{Si}_{\text {PDMS }}: \mathrm{Si}_{\text {MeSD }}$. Without volatilization of MeTEOS a ratio of 10:6:1 is calculated. The NMR measurements indicate the ratio of actual $(4.5 \%)$ to calculated $(15.4 \%)$ mass of siliceous domain is 0.29. If the presence of $\mathrm{SiOH}$ is neglected, the stoichiometry of this material is $\left[26 \times 10^{3} \mathrm{PDMS}\right]\left[\left(\mathrm{MeSiO}_{1.5}\right)\right]_{19.4}$. The ${ }^{29} \mathrm{Si}$ MAS NMR data confirm the high evaporative mass loss of MeTEOS and suggest that the MeSD is composed of $\mathrm{T}^{2}$ and $\mathrm{T}^{3}$ species.

\section{Kinetic study on $26 \times 10^{3} \mathrm{PDMS}(\mathrm{OH})_{2}-$ MeTEOS: contact angles}

Contact angles for water on this material during cure as a function of time are shown in Fig. 3. The change in contact angles shows a pattern parallel to the change in weight, i.e. a faster rate of change occurs in the first week, then a slower rate of change, and finally a leveling off to a final value. As for all thermosets, a characteristic of PDMS hybrid networks is the continuance of crosslinking after gel formation. ${ }^{13}$ The increase in the extent of reaction reduces the mobility of the gel constituents, i.e. the PDMS chains and the siliceous domains. The reduction in mobility at the molecular level enhances the stability of the morphology which favors PDMS chains at the surface. This accounts for the rather large increase of $c a 35^{\circ}$ in $\theta_{\text {rec }}$ during cure (Fig. 3). The small decrease (ca $\left.10^{\circ}\right)$ in $\theta_{\text {adv }}$ during cure is opposite to the change expected. A decrease in surface roughness may account for this observation.

\section{Effects of catalyst concentration}

Effects of catalyst concentration on the kinetics of curing are summarized in Table 3. With catalyst concentration above $0.5 \mathrm{wt} \%$, the mass loss leveled off after 10 days with a total mass loss of $29.0 \%$. With catalyst concentration below $0.5 \mathrm{wt} \%$, the mass loss leveled off after 18 days with a total mass loss of $30.5 \%$. Thus, the gel time and mass loss increase as the catalyst concentration decreases, while the rate of cure decreases with decreased catalyst concentration.

\section{Effects of reactant ratios}

When the reactant ratio was changed from $65.9 \%$ PDMS $(\mathrm{OH})_{2}$ and $33.1 \%$ MeTEOS to $83.1 \%$ $\operatorname{PDMS}(\mathrm{OH})_{2}$ and $15.9 \%$ MeTEOS (both with $1 \%$ DBTDL catalyst) the gel time increased from $100 \mathrm{~min}$ to $270 \mathrm{~min}$. As shown in Fig. 4 for 83.1\% PDMS and $15.9 \%$ MeTEOS, mass loss is rapid in the first three days, then much slower. The total mass loss was $15.5 \%$. The ratio of the weight fraction of siliceous domain in this network

Table 3 Effects of catalyst concentration on the kinetics of the reactions

\begin{tabular}{lcccc}
\hline & Run 1 & Run 2 & Run 3 & Run 4 \\
\hline DPMS(OH) 2 (wt\%) & 66.63 & 66.56 & 66.33 & 66.11 \\
MeTEOS (wt\%) & 33.25 & 33.21 & 33.10 & 0.57 \\
DBTDL (wt\%) & 0.12 & 0.23 & 150 & 120 \\
Gel time (min) & 250 & 200 & 2.90 & 1.90 \\
Mass loss (\%) & 5.77 & 4.09 & 24.73 & 24.63 \\
At gelation & 24.44 & 24.06 & 28.94 & 28.97 \\
At 3 days & 30.52 & 30.12 & 28.97 & 28.98 \\
At 10 days & 30.58 & 30.19 & - & - \\
At 11 days & 30.74 & 30.37 & & \\
At 18 days & & & \\
\hline
\end{tabular}




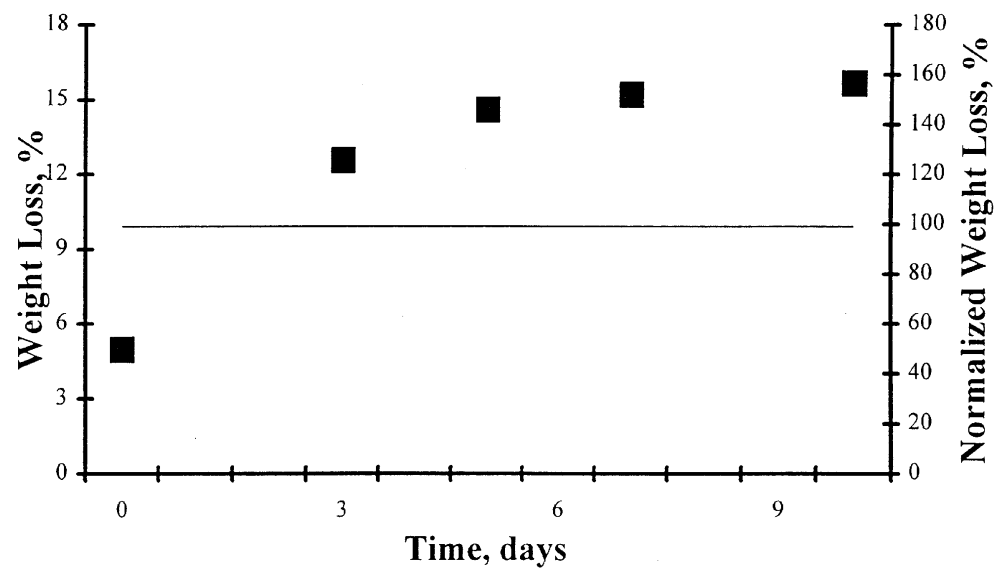

Figure 4 Mass loss as a function of time for the system, comprising $83.1 \%$ PDMS $(\mathrm{OH})_{2}, 15.9 \%$ MeTEOS and $1.0 \%$ DBTDL, in a $10 \mathrm{ml}$ vial, magnetically stirred. Weight is expressed as a percentage of the total weight of reactants. The scale on the right shows values normalized with respect to the calculated loss as ethanol.

$(0.47 \%)$ to the calculated value $(6.7 \%)$ is 0.07 , compared with 0.57 for $65.9 \% \operatorname{PDMS}(\mathrm{OH})_{2}$ and $33.1 \%$ MeTEOS. A similar reduction in mass fraction of siliceous domain was observed when the concentration of the catalyst was $0.1 \mathrm{wt} \%$. Compared with $66.5 \%$ PDMS $(\mathrm{OH})_{2}$ and $33.4 \%$ MeTEOS, a $82.5 \%-17.4 \%$ system showed a longer gel time (140 h vs $4.2 \mathrm{~h}$ ) and a lower efficiency in forming siliceous domains (the ratios for the actual to the calculated weight fractions for the siliceous domain were less than 0.01 and 0.11 , respectively).

\section{Effects of free surface area}

When the reaction vessel was changed from a $10 \mathrm{ml}$ vial to a $50 \mathrm{ml}$ beaker, the free surface increased by a factor of 2.3 , and more vigorous stirring was possible with a larger stir bar. The reaction was carried out with $61.5 \%$ PDMS $(\mathrm{OH})_{2}, \quad 37.6 \%$

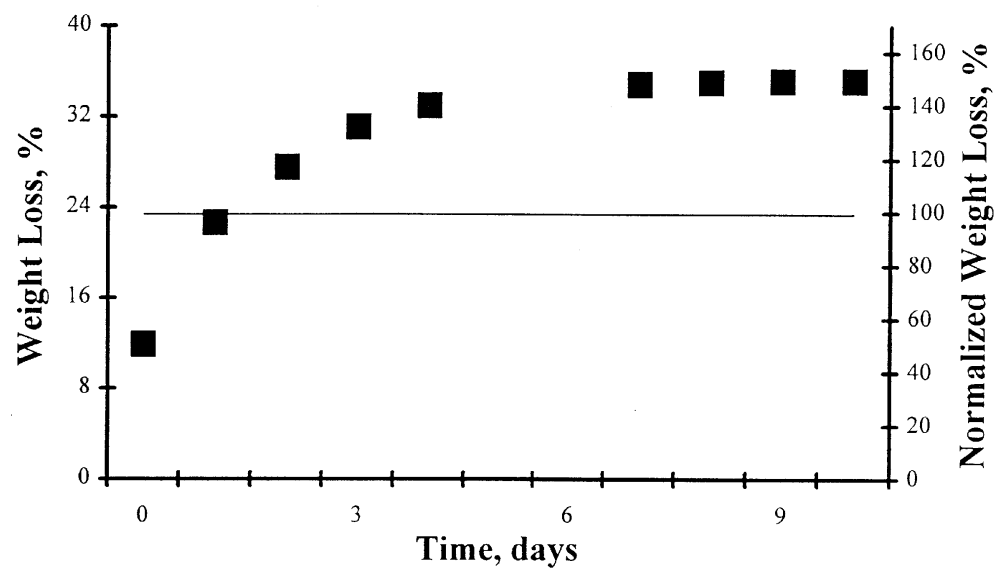

Figure 5 Mass loss as a function of time for the system comprising $61.5 \% \mathrm{PDMS}(\mathrm{OH})_{2}, 37.6 \% \mathrm{MeTEOS}$, and $0.9 \% \mathrm{DBTDL}$, in a $50 \mathrm{ml}$ beaker, magnetically stirred. Weight is expressed as a percentage of the total weight of reactants. The scale on the right shows values normalized with respect to the theoretical maximum loss as ethanol. 
MeTEOS and 0.9\% DBTDL, and the mass loss is shown as a function of time in Fig. 5. The gel time was $90 \mathrm{~min}$. The mass loss at gelation was $11.8 \%$. The mass loss increased rapidly in the first four days, then gradually leveled off after six days. The final mass loss was $35.0 \%$, and the ratio of the actual weight fraction of siliceous domain to the calculated value was 0.22 (i.e. $4.0 \mathrm{wt} \%$ siliceous domain vs $18.5 \%$ calculated). Thus, the larger free surface and more vigorous stirring enhanced the rate of evaporation of MeTEOS, causing lower efficiency in forming a siliceous phase, and a faster rate of mass loss.

In summary, rapid gelation and low MeTEOS loss are favored by the use of a high MeTEOS concentration and a high catalyst concentration and the reduction of free surface area for the reactants in conjunction with faster stirring. With optimized conditions, the gel time (less than $2 \mathrm{~h}$ ) is satisfactory and the efficiency in converting MeTEOS to a siliceous domain is 0.57 .

\section{Mechanical strength}

Young's modulus was evaluated for films prepared with $65.9 \% 26 \times 10^{3} \quad \mathrm{PDMS}(\mathrm{OH})_{2}$ and $33.1 \%$ MeTEOS. The cured material contained $8.9 \%$ siliceous domain and exhibited a modulus of $0.7 \mathrm{MPa}$ and a strain-to-break of $150 \pm 40 \%$. The corresponding value for a commercial RTV (GE RTV 11), which contains $\mathrm{ca} 30 \% \mathrm{CaCO}_{3}$ filter, is $1.8 \mathrm{MPa}$ and $212 \pm 8 \%$ (both obtained with $0.7 \mathrm{~mm} \times 5 \mathrm{~mm} \times 17 \mathrm{~mm}$ strips at a strain rate $0.5 \mathrm{~min}^{-1}$ ). Thus, the mechanical strength of the PDMS-MeTEOS materials is modest.

\section{Stability in water}

The stability in water of a network prepared using $65.9 \% 26 \times 10^{3} \mathrm{PDMS}(\mathrm{OH})_{2}, 33.1 \%$ MeTEOS and $1 \%$ dibutyltin dilaurate was evaluated by immersing a thick film in nanopure water and periodically monitoring the mass of the sample. The rate of mass loss was $2 \%$ per week. Another sample with a similar starting composition but lower catalyst concentration $(0.3 \%)$ exhibited a rate of mass loss of $1 \%$ per week. The suprisingly high rates of weight loss for these materials has shifted our attention to networks utilizing a different siliciousphase precursor.

\section{CONCLUSIONS}

Polydimethylsiloxane (PDMS) hybrid networks have been prepared by the reaction of $\operatorname{PDMS}(\mathrm{OH})_{2}$ and MeTEOS using a dibutyltin dilaurate or dibutyltin diacetate catalyst Initial studies of wettability as measured by contact angles $\theta_{\mathrm{adv}}=106^{\circ}$ and $\theta_{\mathrm{rec}}=96^{\circ}$ ) were encouraging. Kinetic studies showed the reaction rate is dependent on catalyst concentration and on processing conditions. However, evaporative loss of MeTEOS is a major problem under the water-sparse conditions used in preparation of films. This evaporative loss leads to a low MeSD content in films which compromises mechanical properties. Future work is aimed at control of SD composition using alkoxysilanes which are far less volatile. ${ }^{14}$

Acknowledgment This research was supported in part by the Strategic Environmental Research and Development Program (SERDP) and the Office of Naval Research (Scientific Officer Research Program).

\section{REFERENCES}

1. K. Kroyer, British Patent 1307001 (1973).

2. M. Kishihara, K. Nanishi and Y. Yonehara, US Patent 5218 059 (1993).

3. B. McLoughlin, K. Maurice-Riches and E. B. Shone, British Patent 1581727 (1981).

4. A. Milne, US Patent 4025693 (1977).

5. D. R. Ulrich, CHEMTECH, 242 (April 1988).

6. J. E. Mark, CHEMTECH, 242 (April 1989), and references cited therein.

7. J. Wen and G. L. Wilkes, Chem., Mater. 8, 1667 (1996).

8. R. H. Dettre and R. E. Johnson Jr, J. Phys. Chem. 69, 1507 (1965).

9. R. E. Johnson Jr, in: Wettability Berg, J. C. (ed.) Marcel, Dekker, New York, 1993, pp. 1-73.

10. X. Zheng, M. H. Rafailovich, J. Sokolov, X. Zhao, R. M. Briber and S. A. Schwarz, Macromolecules 26, 6431 (1994).

11. C. J. Brinker and G. W. Scherer, Sol-Gel Science, Academic Press, San Diego, 1990, Chapter 5.

12. R. H. Glaser and G. L. Wilkes, J. Non-Cryst. Solids, 113, 73 (1989).

13. P. J. Flory, Principles of Polymer Chemistry, Cornell University Press, New York, 1953, Chapter 9.

14. K. Wynne, T. Ho, E. E. Johnston and S. A. Myers, In preparation. 